\title{
AVALIAÇÃO DA VIDA-DE-PRATELEIRA DE BEBIDAS LÁCTEAS PREPARADAS COM "FAT REPLACERS" (LITESSE E DAIRY-LO)"
}

\author{
Katia SIVIERI ${ }^{2, *}$, Maricê Nogueira de OLIVEIRA ${ }^{2}$
}

\section{RESUMO}

Face ao aumento de peso e ao aparecimento de doenças cardiovasculares na população mundial devido ao consumo de alimentos altamente calóricos, o desenvolvimento de alimentos com baixo ou reduzido teor de gordura torna-se essencial. Estudou-se o efeito da adição de "fat replacers" (Litesse e Dairy-lo) na vida-de-prateleira de bebidas lácteas. No presente trabalho as variáveis independentes Litesse $\left(\mathrm{X}_{1}\right)$ e Dairy-lo $\left(\mathrm{X}_{2}\right)$ foram empregadas nas concentrações 0,50,1,50, 2,50\% em peso, com 7 combinações calculadas e 3 repetições do ponto central utilizando a metodologia de superficie resposta. As bebidas lácteas foram avaliadas através de análises químicas (valor de $\mathrm{pH}$, acidez total titulável, teores de sólidos totais e tirosina) e sensoriais (aparência, sabor e consistência) aos $0,7,14,21$ e 28 dias de armazenamento a $5^{\circ} \mathrm{C}$. Durante a vida-de-prateleira a utilização de diferentes concentrações de Litesse e Dairy-lo não influenciou o comportamento físico-quimico e a aparência das bebidas lácteas estudadas. Entretanto, o sabor foi afetado com o armazenamento. Podese estabelecer 28 dias como o tempo ideal para a vida-de-prateleira das bebidas lácteas estudadas. Os resultados indicam que a utilização do Litesse e Dairy-lo em formulações de bebidas lácteas é perfeitamente viável.

Palavras-chave: bebida láctea; vida-de-prateleira; "fat replacer"; litesse; dairy-lo.

\section{SUMMARY}

SHELF-LIFE EVALUATION OF LATIC BEVERAGES ADDED WITH FAT MIMETICS (LITESSE AND DAIRY-LO). The development of low fat foods is essential, due to the remarkable increase in the levels of overweight and clinical obesity and of cardiovascular health problems worldwide. Were have studied the effect of adding fat replacers (Litesse and Dairy-lo) on the shelf-life of lactic beverages. In the present work, the independent variables Litesse (X1) and Dairy-lo (X2), ranging from 0.50 to $2.50 \%$ (w/w) were studied by Response Surface Methodology (RSM) in a total number of 7 assay combinations and 3 repetitions of the central point. Chemical determinations (pH, total acidity, total solids and tyrosine) and sensorial analyses were carried out in lactic beverages after $0,7,14$ and 28 days of storage at $5^{\circ} \mathrm{C}$. It was observed that, during shelf-life, the use of different concentrations of fat replacers did not affect the physical and chemical behavior, and the appearance of the lactic beverages studied. On the other hand, taste was considered the most affected attribute during storage. A shelf-life of 28 days was established as the best one for the lactic beverages studied. The results indicate that the use of fat replacers in lactic beverage formulations is feasible.

Keywords: lactic beverage; shelf-life; fat replacer; litesse; dairy-lo.

\section{1 - INTRODUÇÃO}

Desde os anos oitenta, muitos consumidores nos EUA e na Europa vêm modificando seus hábitos alimentares por razão de saúde, com redução de quantidades de gordura, açúcar, sal, colesterol e certos aditivos. As indústrias de alimentos observaram esta demanda que, como conseqüência, levou a um rápido crescimento no mercado de alimentos e bebidas dietéticas [27]. Nos Estados Unidos cerca de 36\% dos 100 produtos convencionais são modificados enquanto na Europa este número decresce para $18 \%$. No Brasil, o mercado de dietéticos responde desde 1996 por $1 \%$ do setor de alimentos no país. Dados da Associação Brasileira da Indústria de Alimentos Dietéticos (ABIAD) apontam os produtos de baixas calorias como o segmento que mais cresceu em 1997 [2].

A gordura é um ingrediente chave para os aspectos sensoriais e fisiológicos dos alimentos. Está relacionada com a percepção do sabor, da cremosidade, do aroma e do odor no aparelho bucal, e com a sensação de saciedade após as refeições [20]. Sob o ponto de vista fisiológico, está associada aos ácidos graxos essenciais, às drogas lipofilícas, aos precursores de prostaglandinas e às vitaminas lipossolúveis. Por outro lado, o consumo de altas quantidades de gordura aumenta o desenvolvimento da obesidade e de alguns tipos de câncer e, a ingestão de ácidos graxos saturados está associada ao aumento do colesterol sangüineo e das doenças coronárianas [1].

Segundo DREWNOWSKI [10] a maioria das pessoas estão informadas sobre a importância de se reduzir o consumo da gordura na alimentação, no entanto a adesão à dietas alimentares com baixo teor de gordura continua pequena.

Uma alternativa para solucionar a redução de sabor dos produtos com baixo teor de gordura seria a utilização de "fat replacers", proporcionando assim redução da gordura e mantendo a textura e o sabor dos seus similares com teor normal de gordura [24].

Diferentes tipos de "fat replacers" estão disponíveis no mercado e sua classificação está baseada, principalmente, na natureza química e na origem do produto juntamente com seu valor energético. Eles são tecnicamente divididos em carboidratos, incluindo produtos à base de fibras; proteínas modificadas que possuam boas propriedades emulsificantes ou geleificantes aliadas a baixo valor energético; compostos com ligações éster modificadas e que fornecem propriedades

\footnotetext{
${ }^{1}$ Recebido para publicação em 20/02/01. Aceito para publicação em 17/10/01.

${ }^{2}$ Faculdade de Ciências Farmacêuticas - Universidade de São Paulo. Departamento de Tecnologia Bioquímico Farmacêutica. Av. Prof. Lineu Prestes, 580, BL 16, CEP 05508-000-São Paulo-SP. E-mail: katiasiv@usp.br

* A quem a correspondência deve ser enviada.
} 
semelhantes à gordura ou ainda, gorduras naturais e não calóricas [27].

Dos produtos comercializados como "fat replacers", os iogurtes foram os que obtiveram a melhor aceitação no mercado americano, sendo que atualmente $84,2 \%$ dos iogurtes vendidos são produzidos com substitutos de gordura [14].

Bebidas lácteas "light" podem ser produzidas utilizando um método único de fabricação ou a combinação de vários como: a redução do conteúdo de gordura e de sólidos não gordurosos, o uso de agentes estabilizantes ou, de volume, de baixa caloria, o emprego de adoçantes de baixa caloria e a substituição de gordura [28].

Atualmente os iogurtes desnatados ou semi-desnatados vêm ganhando popularidade devido ao aumento na demanda de produtos de baixas calorias. A qualidade destes produtos depende da textura e do corpo, pois a quantidade de sólidos é muito baixa. Assim, é comum o uso de estabilizantes para melhorar a textura e reduzir a separação de soro. Outro método visando aumentar o conteúdo de sólidos totais é a adição de caseinatos e concentrados proteicos de soro [18].

O termo bebidas lácteas à base de soro tem sentido amplo e pode englobar uma série de produtos, fabricados com leite e soro [21]. Esses produtos não receberam ainda caracterização precisa. Segundo a resolução GMC 47/97, aprovada no Subgrupo 3 do MERCOSUL, entende-se por leites fermentados os produtos adicionados ou não de outras substâncias alimentícias, obtidos por coagulação e diminuição do $\mathrm{pH}$ do leite, ou leite reconstituído, adicionado ou não de outros produtos lácteos, por fermentação láctica mediante a ação de cultivos de microrganismos específicos [7]. Assim, bebidas lácteas fermentadas à base de soro são basicamente uma mistura de iogurte e soro.

A tecnologia de fabricação de bebidas lácteas baseia-se na mistura de iogurte e soro em proporções adequadas, seguida da adição de ingredientes como aromatizantes, corantes, edulcorantes, polpa de frutas e outros, de acordo com a formulação do produtor.

A secagem para obtenção do soro em pó utiliza equipamentos que não estão disponiveis nos laticínios de pequeno e médio porte, por necessitar de alto investimento para compra de equipamento e mão-de-obra especializada para a operação. Por outro lado, a elaboração de bebidas com soro líquido envolve equipamentos e acessórios comuns, encontrados na maioria dos laticínios. Portanto, a fabricação de bebidas lácteas no Brasil usando soro líquido tornou-se uma opção atrativa.

Do ponto de vista de vida-de-prateleira, a qualidade dos alimentos é definida por parâmetros fisiológicos, valores nutricionais e atributos sensoriais como cor, sabor e textura ou consistência. A diminuição da qualidade e a redução de vida-de-prateleira podem ser conseqüência do efeito de uma ou mais destas propriedades [22].

No desenvolvimento de novos produtos um ponto chave é a determinação da vida-de-prateleira, sendo que esta pode ser definida como o tempo decorrido entre a produção e a embalagem do produto até o ponto que este se torna inaceitável ao consumo [11]. Inicialmente identificam-se quais são as características dos ingredientes, as condições de processos e de estocagem que poderão influenciar na vida-de-prateleira do produto estudado. A seguir, monitorando-se e controlando-se os parâmetros de processo, pode-se determinar exatamente o final do tempo de vida-de-prateleira, ou seja, o momento em que o produto não é mais seguro para o consumo [15].

O objetivo deste trabalho foi avaliar o tempo de vidade-prateleira de bebidas lácteas preparadas com "fat replacers" (Litesse e Dairy-lo).

\section{2 - MATERIAIS E MÉTODOS}

\section{1 - Matéria-prima}

As matérias-primas utilizadas foram: leite desnatado pasteurizado (Paulista S/A, São Paulo, Brasil), soro de queijo minas frescal (produzido no Laboratório de Tecnologia de Alimentos da Faculdade de Ciências Farmacêuticas-USP), aromatizante de morango (Givaudan Roure, São Paulo, Brasil), corante de morango (São Paulo, Brasil), cultura láctica mista de Streptococcus salivarius e Lactobacillus delbrueckii subsp. bulgaricus na forma liofilizada, Rich (Chr. Hansen, Valinhos, Brasil), goma carragena (SBI, Campinas, Brasil), litesse (Cultor-Danisco, São Paulo, Brasil) e dairy-lo (Cultor-Danisco, São Paulo, Brasil), mix de edulcorantes contendo aspartame, ciclamato e sacarina (Lowcucar, Maringá,Brasil) e polpa de morango (IFF, Rio de Janeiro, Brasil).

\section{2 - Obtenção da bebida láctea}

O iogurte foi elaborado utilizando leite desnatado pasteurizado adicionado dos "fat replacers", em concentrações definidas de acordo com o delineamento experimental. A mistura (2L) foi aquecida em chapa de aquecimento por $10 \mathrm{~min}$ a $90^{\circ} \mathrm{C}$ e, a seguir, resfriada em banho de gelo até que a temperatura atingisse $43^{\circ} \mathrm{C}$ para a adição de $3 \%$ de inóculo previamente preparado. A mistura foi agitada e levada à estufa $\mathrm{BOD}$ a $42^{\circ} \mathrm{C}$ até que acidez do iogurte atingisse $70^{\circ} \mathrm{D}$ quando foi feita a quebra do coágulo agitando-se de forma mecânica o produto durante 30 s. Adicionou-se $0,1 \%$ de goma carragena ao soro preparado. Após repouso de $15 \mathrm{~min}$, procedeu-se a agitação por $15 \mathrm{~s}$ e, a seguir, a solução foi aquecida a $85^{\circ} \mathrm{C}$ por $30 \mathrm{~min}$ sob agitação visando a completa hidratação da goma.

Após a elaboração do iogurte e do soro, estes foram submetidos à determinação de sólidos totais com vistas à padronização da bebida em cerca de $10 \%$ de sólidos totais. O cálculo da quantidade de iogurte e de soro utilizado na mistura foi realizado segundo o método dos quadrados de Pearson [29]. As proporções de iogurte e de soro utilizadas em cada experimento podem ser observadas na Tabela 1. Após a mistura do iogurte e do soro foram adicionados os demais ingredientes (polpa de morango, edulcorante, aromatizante e corante) se- 
gundo a formulação apresentada na Tabela 2. As bebidas lácteas foram envasadas em copos plásticos termomoldáveis de $100 \mathrm{~mL}$, utilizando seladora manual Selopar (Brasholanda, Pinhais, Brasil) e armazenadas a $5^{\circ} \mathrm{C}$ durante 28 dias.

TABELA 1. Quantidade de soro, iogurte (\%) utilizados nas formulações de bebidas lácteas estudadas.

\begin{tabular}{|c|c|c|c|c|c|c|}
\hline \multirow[t]{3}{*}{ Experimento } & \multirow{2}{*}{\multicolumn{2}{|c|}{$\begin{array}{l}\text { Variáveis } \\
\text { codificadas }\end{array}$}} & \multicolumn{2}{|c|}{ Variaveis originais } & \multirow{3}{*}{$\begin{array}{r}\text { Soro } \\
(\%)\end{array}$} & \multirow{3}{*}{$\begin{array}{c}\text { Iogurte } \\
(\%)\end{array}$} \\
\hline & & & Litesse & Dairy-lo & & \\
\hline & $\mathbf{X} 1$ & $\mathbf{X} 2$ & & & & \\
\hline 1 & -1 & -1 & 0,50 & 0,50 & 12,01 & 87,99 \\
\hline 2 & -1 & 1 & 0,50 & 2,50 & 31,01 & 68,98 \\
\hline 3 & 1 & -1 & 2,50 & 0,50 & 25,68 & 74,31 \\
\hline 4 & 1 & 1 & 2,50 & 2,50 & 47,65 & 52,34 \\
\hline 5 & 0 & 0 & 1,50 & 1,50 & 36,40 & 63,60 \\
\hline 6 & 0 & 0 & 1,50 & 1,50 & 23,91 & 76,08 \\
\hline 7 & 0 & 0 & 1,50 & 1,50 & 33,33 & 66,66 \\
\hline
\end{tabular}

TABELA 2. Formulação básica da bebida láctea.

\begin{tabular}{lc}
\hline \multicolumn{1}{c}{ Ingrediente } & Quantidade (\%) \\
\hline Aromatizante de morango & 0,400 \\
Corante de morango cordianil & 0,300 \\
Goma carragena & 0,100 \\
Mix de edulcorantes & 0,029 \\
Polpa de morango & 5,000 \\
\hline
\end{tabular}

\section{3 - Planejamento estatístico dos ensaios experi- mentais}

Os ensaios experimentais foram realizados segundo um projeto ortogonal de primeiro grau, de acordo com BOX, HUNTER, HUNTER [5]. A Tabela 3 mostra as variáveis independentes e os niveis de variação usados nos experimentos.

TABELA 3. Variáveis independentes e niveis adotados experimentalmente.

Níveis codificados das variáveis ${ }^{\text {a }}$

\begin{tabular}{cccccc} 
Variáveis originais & Unidade & Símbolo & -1 & 0 & 1 \\
\hline Litesse & $\%$ & $\mathrm{~L}$ & 0,50 & 1,50 & 2,50 \\
Dairy-lo & $\%$ & $\mathrm{DL}$ & 0,50 & 1,50 & 2,50
\end{tabular}

a- A passagem do nivel da variável codificada para a original é dada pelas seguintes equações:

$X_{1}=\frac{\mathrm{L}+1,5}{1} \quad$ e $\quad X_{2}=\frac{\mathrm{DL}+1,5}{1}$

$X_{1}, X_{2}=$ variáveis codificadas

Os resultados do perfil de otimização da concentração dos "fat replacers" Litesse e Dairy-lo em bebidas lácteas podem ser vistos em SIVIERI \& OLIVEIRA [25].

\section{4 - Avaliação da matéria-prima e do produto pro- cessado}

O leite e o soro foram submetidos às análises de valor de $\mathrm{pH}$, teores de acidez, densidade, gordura e sólidos totais conforme CASE et al. [9].

As bebidas lácteas foram submetidas às análises de valor de $\mathrm{pH}$ e teor de acidez [9] e de tirosina [13] aos $0,7,14,21$ e 28 dias de armazenamento conforme preconizado por [11]. Todas determinações foram realizadas em triplicata.

\section{5 - Análise sensorial}

As avaliações sensoriais das amostras de bebidas lácteas foram realizadas por uma equipe de 8 provadores, previamente selecionados e treinados para este tipo de análise, utilizando uma escala de qualidade estruturada de cinco pontos, sendo: 1 ponto péssimo; 2 pontos ruim; 3 pontos regular; 4 pontos bom; 5 pontos ótimo [19]. Esta foi previamente definida pelos provadores, como indicado na Tabela 4.

TABELA 4. Determinações dos padrões de qualidade utilizadas na análise sensorial das bebidas lácteas.

\begin{tabular}{|c|c|c|}
\hline Atributo & Ótimo (5) & Péssimo (1) \\
\hline Aparência & $\begin{array}{l}\text { Ausência de pontos brancos, produto } \\
\text { homogêneo, ausência de separação, } \\
\text { cor rosa característico. }\end{array}$ & $\begin{array}{l}\text { Presença de pontos } \\
\text { brancos, presença de } \\
\text { separação, cor alterada. }\end{array}$ \\
\hline Consistência & $\begin{array}{l}\text { Típica de produto batido, ou seja, uma } \\
\text { consistência agradável ao beber. }\end{array}$ & $\begin{array}{l}\text { Muito fluida ou muito } \\
\text { consistente. }\end{array}$ \\
\hline Sabor & $\begin{array}{l}\text { Não muito ácido, sabor característico } \\
\text { de bebidas lácteas fermentadas. }\end{array}$ & $\begin{array}{l}\text { Muito ácido, amargo, } \\
\text { residual ("after taste"). }\end{array}$ \\
\hline
\end{tabular}

As bebidas lácteas foram submetidas à análise sensorial de aparência, consistência e sabor aos 0 e aos 28 dias de armazenamento a $5^{\circ} \mathrm{C}$.

\section{6 - Estimativa da vida-de-prateleira}

A estimativa da vida-de-prateleira foi efetivada estudando-se a taxa de incremento ou de decaimento das respostas valor de $\mathrm{pH}$, teor de acidez e teor de tirosina em função do tempo de armazenamento, por regressão linear simples, mediante programa Excel 97.

\section{3 - RESULTADOS E DISCUSSÃO}

\section{1 - Caracterização do leite e do soro}

Os resultados das avaliações físico-químicas dos leites e dos soros utilizados na elaboração das bebidas lácteas estão apresentados nas Tabelas 5 e 6 , respectivamente.

Segundo TRONCO [30], a qualidade do leite pode ser evidenciada por meio de determinações físico-químicas. Assim, através de exames quantitativos, é possível identificar a adição de substâncias adulterantes, a eventual presença de conservantes e mesmo fazer o cálculo aproximado do rendimento industrial. 
De acordo com o Regulamento de Inspeção de Produtos de Origem Animal (RISPOA) pelo artigo 476, considera-se o leite desnatado normal o que apresenta teor de gordura $(0,1$ a $0,5 \%)$; acidez: $\left(15\right.$ a $\left.20^{\circ} \mathrm{D}\right)$; densidade $\left(1,031\right.$ a $\left.1,034 \mathrm{~g} / \mathrm{cm}^{3}\right)$ e extrato seco total $(\geq 8,5)[6]$.

Os resultados médios \pm desvio padrão do valor de $\mathrm{pH}$, acidez, densidade, gordura e sólidos totais do leite foram $6,68 \pm 0,08,19,31 \pm 0,53^{\circ} \mathrm{D}, 1,033 \pm 0,001 \mathrm{~g} /$ $\mathrm{cm}^{3}, 0,17 \pm 0,11 \%, 9,00 \pm 0,29 \%$, respectivamente $(\mathrm{Ta}-$ bela 5), sendo considerados normais segundo a RISPOA.

TABELA 5. Valores médios* das análises dos leites desnatados esterilizados utilizados na elaboração das bebidas

\begin{tabular}{cccccc}
\hline Experimento & $\mathrm{pH}$ & $\begin{array}{c}\text { Acidez } \\
\left({ }^{\circ} \mathrm{D}\right)\end{array}$ & $\begin{array}{c}\text { Densidade } \\
\left(\mathrm{g} / \mathrm{cm}^{3}\right)\end{array}$ & $\begin{array}{c}\text { Gordura } \\
(\%)\end{array}$ & $\begin{array}{c}\text { Sólidos Totais } \\
(\%)\end{array}$ \\
\hline 1 & 6,72 & 19,57 & 1,034 & 0,10 & 9,16 \\
2 & 6,73 & 19,08 & 1,035 & 0,20 & 9,10 \\
3 & 6,72 & 19,57 & 1,034 & 0,10 & 9,16 \\
4 & 6,50 & 18,19 & 1,031 & 0,20 & 8,56 \\
5 & 6,65 & 19,66 & 1,034 & 0,40 & 8,93 \\
6 & 6,72 & 19,57 & 1,034 & 0,10 & 9,16 \\
7 & 6,72 & 19,57 & 1,034 & 0,10 & 9,16 \\
\hline
\end{tabular}

* média de 3 determinações

Segundo ZADOW [31], o soro pode ser considerado como doce quando apresenta valor de $\mathrm{pH}$ entre 5,8 a 6,6 e teor de acidez de 0,10 a 0,20\%. A composição do soro varia muito dependendo do processo de fabricação e do tipo de queijo. De maneira geral, o soro doce é composto por 93 a $94 \%$ de água, 4,5 a 5,0\% de lactose, 0,8 a $1,0 \%$ de cinzas e 0,1 a $0,5 \%$ de gordura [23].

Os valores médios de $\mathrm{pH}$ e os teores médios de acidez encontrados nos soros utilizados na obtenção de bebidas lácteas foram $6,54 \pm 0,09$ e $12,11 \pm 0,55^{\circ} \mathrm{D}$, respectivamente. Estes dados estão dentro da faixa caracterizada como soro doce (Tabela 6).

PENNA [21] analisou soros de queijos para elaboração de bebidas lácteas sendo que os valores encontrados foram: densidade $1,027 \mathrm{~g} / \mathrm{cm}^{3}$, teor de acidez $9,18^{\circ} \mathrm{D}$, valor de $\mathrm{pH} 6,43$, gordura $1,5 \%$ e, teor de sólidos totais $6,29 \%$. Valores semelhantes foram encontrados em soros obtidos neste trabalho (Tabela 6).

TABELA 6. Valores médios * das análises dos soros utilizados na elaboração das bebidas lácteas.

\begin{tabular}{cccccc}
\hline Experimentos & $\mathbf{p H}$ & $\begin{array}{c}\text { Acidez } \\
\left({ }^{\circ} \mathbf{D}\right)\end{array}$ & $\begin{array}{c}\text { Densidade } \\
\left(\mathbf{g} / \mathbf{c m}^{\mathbf{3}}\right)\end{array}$ & $\begin{array}{c}\text { Gordura } \\
\mathbf{( \% )}\end{array}$ & $\begin{array}{c}\text { Sólidos Totais } \\
\mathbf{( \% )}\end{array}$ \\
\hline 1 & 6,52 & 12,48 & 1,026 & 0,10 & 6,34 \\
2 & 6,77 & 11,29 & 1,026 & 0,10 & 6,33 \\
3 & 6,50 & 12,48 & 1,026 & 0,10 & 6,50 \\
4 & 6,50 & 11,33 & 1,026 & 0,10 & 6,25 \\
5 & 6,50 & 12,36 & 1,026 & 0,10 & 6,50 \\
6 & 6,50 & 12,36 & 1,026 & 0,10 & 6,50 \\
7 & 6,52 & 12,48 & 1,026 & 0,10 & 6,34 \\
\hline
\end{tabular}

* média de 3 determinações

\section{2 - Aspectos físico-químicos das bebidas lácteas}

Os resultados das avaliações físico-químicas podem ser observados nas Figuras 1, 2 e 3.
Na Figura 1 pode-se observar que os valores de $\mathrm{pH}$ diminuem ligeiramente nos 7 primeiros dias de armazenamento mantendo-se praticamente constantes até o $28^{\circ}$ dia. Os valores de $\mathrm{pH}$ variaram entre 4,6 a 4,0 após a fabricação e entre 4,5 a 3,9 após 28 dias de armazenamento. Na Tabela 7 observa-se a taxa de diminuição dos valores de $\mathrm{pH}$ e seu respectivo valor de coeficiente de determinação $\left(\mathrm{r}^{2}\right)$. Nos 7 experimentos analisados verificou-se que a taxa de diminuição do $\mathrm{pH}$ é muito baixa independentemente da formulação utilizada. $\mathrm{O}$ valor de $\mathrm{r}^{2}$ é baixo devido à queda do valor de $\mathrm{pH}$ nos 7 primeiros dias de estocagem.

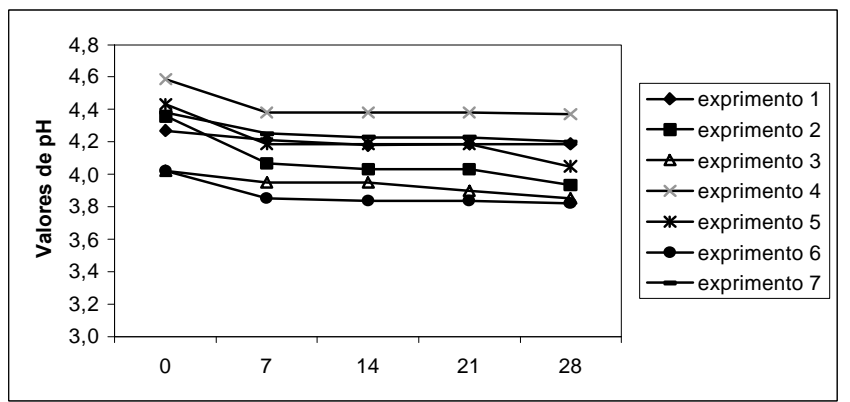

FIGURA 1. Valores de $\mathrm{pH}$ das bebidas lácteas referentes a 7 experimentos durante 28 dias de armazenamento.

TABELA 7. Cinética do comportamento do valor de $\mathrm{pH}$ das bebidas lácteas durante 28 dias de armazenamento a $5^{\circ} \mathrm{C}$.

\begin{tabular}{ccccc}
\hline Experimento & Litesse $(\%)$ & Dairy-lo (\%) & $\begin{array}{c}\text { Taxa k } \\
\text { (Unidades de } \mathrm{pH} / \mathrm{dia})\end{array}$ & $\mathrm{r}^{2}$ \\
\hline 1 & 0,50 & 0,50 & $-0,018$ & 0,613 \\
2 & 0,50 & 2,50 & $-0,090$ & 0,746 \\
3 & 2,50 & 0,50 & $-0,039$ & 0,943 \\
4 & 2,50 & 2,50 & $-0,044$ & 0,534 \\
5 & 1,50 & 1,50 & $-0,076$ & 0,768 \\
6 & 1,50 & 1,50 & $-0,041$ & 0,619 \\
7 & 1,50 & 1,50 & $-0,038$ & 0,726 \\
\hline
\end{tabular}

Resultados semelhantes foram encontrados por ELLIS [11], que analisou três diferentes marcas de iogurtes comerciais durante 28 dias de armazenamento. Os valores de $\mathrm{pH}$ no tempo zero encontraram-se entre 4,1 e 4,2 e, aos 28 dias de armazenamento, entre 3,9 e 4,0 . Durante os 28 dias de armazenamento houve uma pequena variação no valor de $\mathrm{pH}$ como os resultados obtidos para as bebidas lácteas (Figura 1).

Segundo ELLIS [11], os microrganismos presentes em iogurtes continuam viáveis, e mesmo mantendo o produto a uma temperatura de $5^{\circ} \mathrm{C}$, estes continuam se reproduzindo e acidificando o meio. Portanto, para se estabelecer se um iogurte é próprio para consumo devese verificar o valor de $\mathrm{pH}$ e o teor de acidez.

De acordo com SOUZA [26], a acidez do iogurte é muito variável e influencia largamente seu consumo. Assim, valores como 0,7 a $1,25 \%$ de ácido láctico ou o pH de 4,6 a 3,7 são comuns. Entretanto, o autor considera como ideal acidez entre 0,7 e $0,9 \%$ ou pH entre 4,0 a 4,4 . Valores semelhantes aos considerados como ideais foram encontrados nas bebidas lácteas preparadas, mesmo após 28 dias de armazenamento (Figura 1). 
Na Figura 2 pode-se observar o comportamento dos teores de acidez durante os 28 dias de armazenamento, que estão de acordo com a Resolução GMC 47/97 sendo considerados como próprios para consumo pela Legislação Brasileira [6].

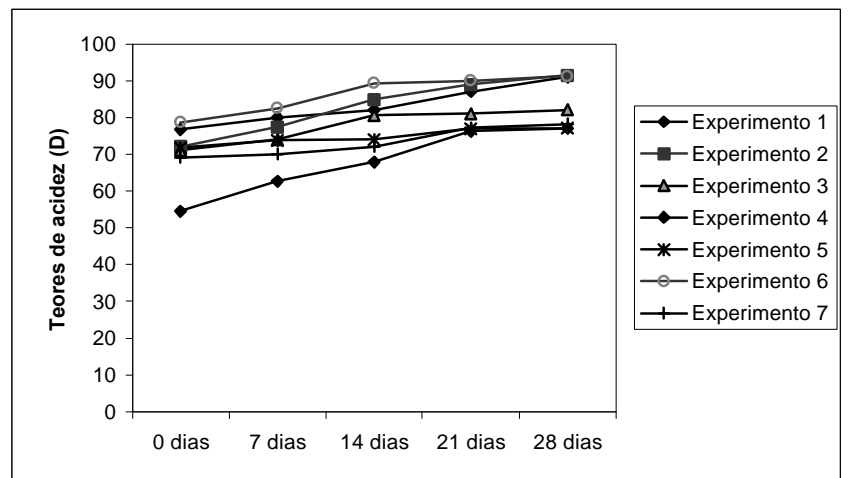

FIGURA 2. Teores de acidez $\left({ }^{\circ} \mathrm{D}\right)$ das bebidas lácteas durante 28 dias de armazenamento a $5^{\circ} \mathrm{C}$.

Na Tabela 8 pode-se observar a taxa de aumento do teor de acidez durante os 28 dias de armazenamento. Comparando-se com os valores encontrados para valor de $\mathrm{pH}$ (Tabela 7 estes são inversamente proporcionais. Mesmo sendo esperados estes resultados, as taxas encontradas para teores de acidez são bem superiores às de $\mathrm{pH}$.

TABELA 8. Cinética do comportamento do teor de acidez $\left({ }^{\circ} \mathrm{D}\right)$ das bebidas lácteas durante 28 dias de armazenamento a $5^{\circ} \mathrm{C}$.

\begin{tabular}{ccccc}
\hline Experimento & Litesse $(\%)$ & Dairy-lo $(\%)$ & $\begin{array}{c}\text { Taxa k } \\
\left({ }^{\circ} \mathrm{D} / \mathrm{dia}\right)\end{array}$ & $\mathrm{r}^{2}$ \\
\hline 1 & 0,50 & 0,50 & 3,839 & 0,671 \\
2 & 0,50 & 2,50 & 4,981 & 0,965 \\
3 & 2,50 & 0,50 & 3,146 & 0,901 \\
4 & 2,50 & 2,50 & 5,895 & 0,943 \\
5 & 1,50 & 1,50 & 1,622 & 0,899 \\
6 & 1,50 & 1,50 & 2,808 & 0,877 \\
7 & 1,50 & 1,50 & 3,146 & 0,901 \\
\hline
\end{tabular}

Observando a Figura 2 pode-se verificar que o aumento da acidez é mais linear quando comparada à diminuição do valor de pH (Figura 1) e comprovado pelos melhores valores de coeficientes de determinação $\left(\mathrm{r}^{2}\right)$ Em relação aos experimentos, estes mostraram acidificação semelhante durante o armazenamento (Figura 2). Portanto a utilização de diferentes formulações não influenciou na alteração do valor de $\mathrm{pH}$ e teor de acidez.

Segundo BARRANTES, TAMIME, SWORD [4], quando se utiliza Dairy-lo na formulação de iogurtes formase um sistema tampão que estabiliza o sistema, pois este é constituído de proteína. Assim fica inviável controlar a acidificação do meio através de medidas de valor de $\mathrm{pH}$ e o mais apropriado é a utilização da verificação da acidez total titulável.

No experimento 4 no qual utilizou-se os "fat-replacer" em proporções iguais e no maior nivel (2,5\%), a acidez inicial da bebida foi a mais baixa. Entretanto, foi a bebida que apresentou a maior taxa de aumento da acidez $(\mathrm{k}=5,895)$. Assim, pode-se deduzir que neste experi- mento, quanto menor a acidez inicial da bebida maior é o aumento da acidez durante a vida-de-prateleira.

Na Tabela 9 observa-se a cinética do comportamento do teor de tirosina das bebidas lácteas durante 28 dias de armazenamento. As taxas de aumento e os valores de $r^{2}$ dos teores de tirosina foram de maneira geral baixos, mostrando que os resultados não se comportaram de uma maneira linear durante toda a vida-de-prateleira, apresentando uma tendência exponencial característica de reações de proteólise.

TABELA 9. Cinética do comportamento do teor de tirosina (mg/100mL de bebidas lácteas) das bebidas lácteas durante 28 dias de armazenamento a $5^{\circ} \mathrm{C}$.

\begin{tabular}{|c|c|c|c|c|}
\hline Experimento & Litesse (\%) & Dairy-lo (\%) & $\begin{array}{c}\text { Taxa }(\mathrm{k}) \\
\text { (mg tirosina/ } 100 \mathrm{~mL} \text { de } \\
\text { bebidas lácteas/dia) }\end{array}$ & $\mathrm{r}^{2}$ \\
\hline 1 & 0,50 & 0,50 & 0,240 & 0,413 \\
\hline 2 & 0,50 & 2,50 & 0,653 & 0,774 \\
\hline 3 & 2,50 & 0,50 & 1,107 & 0,872 \\
\hline 4 & 2,50 & 2,50 & 0,429 & 0,858 \\
\hline 5 & 1,50 & 1,50 & 0,446 & 0,527 \\
\hline 6 & 1,50 & 1,50 & 1,593 & 0,864 \\
\hline 7 & 1,50 & 1,50 & 0,721 & 0,713 \\
\hline
\end{tabular}

Observando a Figura 3, pode-se verificar que a maioria das bebidas estudadas se comportam de maneira linear até 14 dias de armazenamento, atingindo um patamar no qual o teor de tirosina permanece praticamente constante. O mesmo não ocorreu no experimento 5, que apresentou a menor taxa de acidificação e não ocorrendo proteólise até 21 dias de armazenamento. Segundo GURGEL \& OLIVEIRA [12], o poder proteolitico das culturas lácteas é importante, pois a proteólise muito forte pode causar defeitos como diminuir a consistência do iogurte favorecendo a relação entre os microrganismos lácticos usados ou acidez excessiva como o aparecimento do sabor amargo.

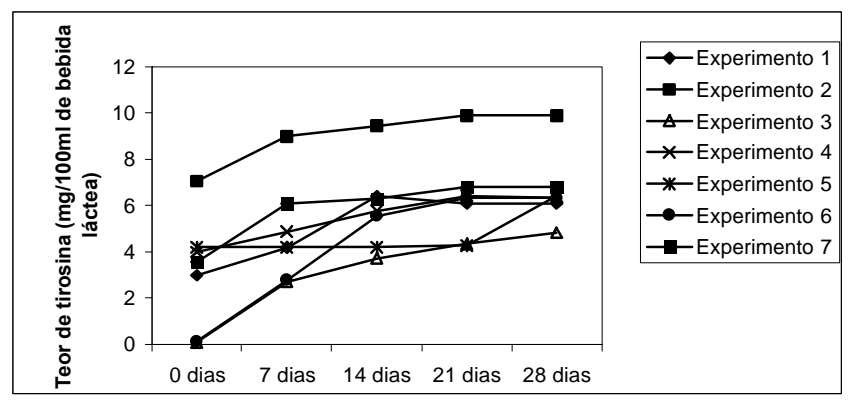

FIGU'RA 3. Teores de tirosina $(\mathrm{mg} / 100 \mathrm{~mL}$ de bebida láctea) das bebidas lácteas durante a vida-de-prateleira.

A melhor aceitação do iogurte ocorre quando os teores de tirosina encontram-se na faixa de 2,62 a 4,68mg/ $100 \mathrm{~g}$ [12]. Os valores observados nas bebidas lácteas analisadas variaram de $4,82 \mathrm{mg} / 100 \mathrm{~mL}$ (experimento 3) a $9,88 \mathrm{mg} / 100 \mathrm{~mL}$ de bebida láctea (experimento 2), aos 28 dias de armazenamento. Destes, o experimento 2 foi o que mais se distanciou da faixa estipulada como ideal pelos autores. Como não foram realizadas análises microbiológicas para determinar a atividade das culturas e proporção entre os microrganismos, pode-se 
supor que neste experimento 2 a cultura apresentava maior poder proteolitico (Figura 3).

\section{3.- Aspectos sensoriais}

Os resultados das avaliações sensoriais (aparência, sabor e consistência) das bebidas lácteas são mostrados nas Figuras 4, 5 e 6.

Em relação à aparência das bebidas lácteas, os experimentos se comportaram de forma semelhante. Utilizou-se diferentes proporções de Litesse e Dairy-lo, assim poderiam ocorrer problemas na fermentação como a formação de grumos, a sinerese e outros.

Os membros do painel sensorial consideraram a aparência de todas as bebidas dos diferentes experimentos como boas (valor 4) ou ótimas (valor 5) (Figura 4). Durante o treinamento foi estipulado que, para a aparência da bebida ser considerada ótima, o produto não deveria apresentar pontos brancos, estar bem homogênea, sem separação de soro e apresentar cor rosa característica. Após 28 dias de armazenamento as bebidas continuaram sendo consideradas boas, mostrando que o armazenamento não influenciou na aparência das bebidas lácteas.

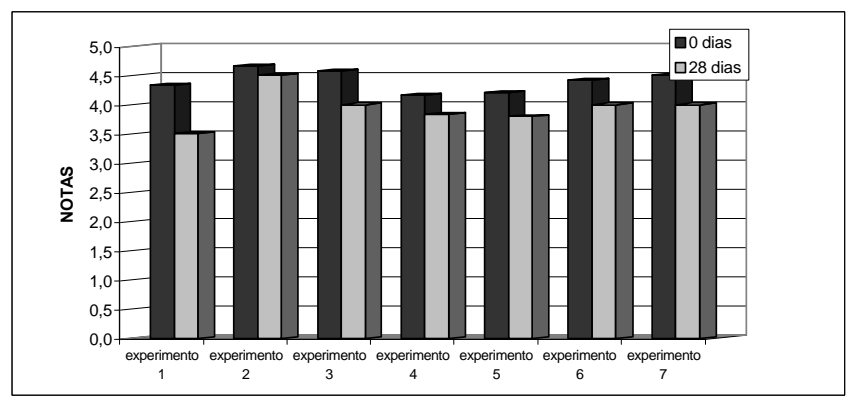

FIGURA 4. Avaliação sensorial da aparência das bebidas lácteas no dia da preparação e após 28 dias de armazenamento.

A aparência é a primeira impressão que o consumidor tem em relação a um produto e é considerada como definitiva para estipular a vida-de-prateleira do mesmo, pois este não pode ser comercializado se sua aparência for ruim, mesmo se apresentar ótimo sabor. Entretanto, em uma pesquisa que examinou os fatores determinantes para escolha dos alimentos, os participantes classificaram o sabor (80\%) como mais importante que o aspecto nutritivo (75\%) [24].

Os julgadores consideraram as bebidas lácteas como tendo um sabor de bom a ótimo imediatamente após sua preparação (zero dia de armazenamento). A bebida láctea do experimento $2(0,5 \%$ Litesse e 2,5\% Dairy-lo) foi considerada a melhor (5 = ótimo) (Figura 5).

Após 28 dias de armazenamento as bebidas lácteas dos experimentos foram consideradas de ruim (2) a razoável (3). Os produtos obtidos conforme os experimentos 2 e 3 foram os que apresentaram os piores sabores após os 28 dias de armazenamento, sendo que os produtos dos demais experimentos foram considerados razoáveis. Segundo MAN, JONES [16], o aumento da acidez pode alterar o perfil de sabor dos iogurtes. MARTIN et al. [17] analisaram sensorialmente iogurtes batidos com baixo teor de gordura no dia da preparação e após 21 dias de armazenamento. Após este prazo, os autores verificaram que os iogurtes apresentaram-se mais ácidos e com sabor amargo. O desenvolvimento do sabor amargo foi devido à atividade proteolítica do Lactobacillus bulgaricus.

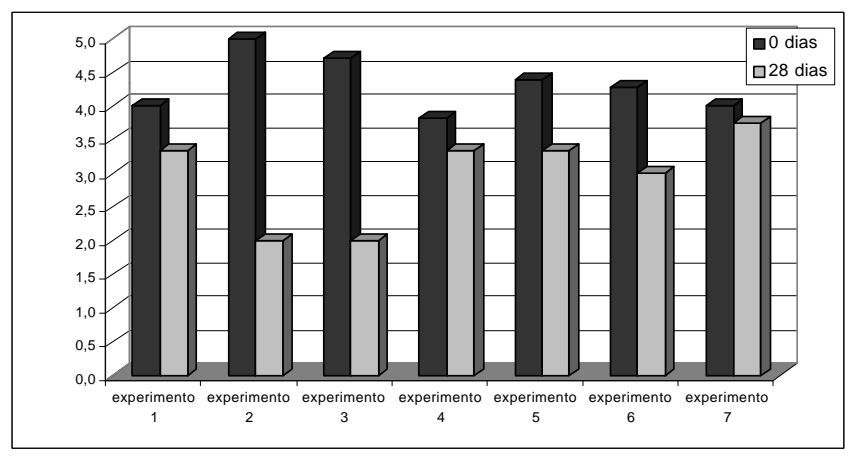

FIGURA 5. Avaliação sensorial do sabor das bebidas lácteas no dia da preparação e após 28 dias de armazenamento.

Correlacionando os resultados do teor de tirosina e a avaliação sensorial do sabor, observou-se que no vigésimo oitavo dia de armazenamento as bebidas lácteas estudadas encontravam-se com teor de tirosina superior a $5 \mathrm{mg} / 100 \mathrm{~mL}$ de bebida, com exceção do experimento 3. Este valor é superior à faixa recomendada por GURGEL, OLIVEIRA [12]. Portanto, a perda de qualidade sensorial do sabor pode estar relacionada com o alto teor de tirosina após 28 dias de armazenamento.

BARRANTES, TAMIME, SWORD [4] realizaram análises sensoriais em iogurtes produzidos com vários tipos de miméticos de gorduras. Cem pessoas provaram os iogurtes, sendo que a maioria preferiu os iogurtes produzidos com o Litesse.

Os resultados da avaliação da consistência no dia da preparação e após 28 dias de armazenamento podem ser observados na Figura 6. Os julgadores consideraram as bebidas lácteas entre razoáveis (valor 3) e boas (valor 4) no dia da preparação e após 28 dias de armazenamento. As bebidas dos experimentos 4, 5 e 7 foram as que tiveram as menores perdas de consistência durante a estocagem.

A análise sensorial mostrou que houve uma pequena diminuição da consistência das bebidas. Os resultados obtidos estão de acordo com CASALIS [8] e BARRANTES, TAMIME [3] que mencionam que variações na consistência de iogurtes podem ocorrer durante a estocagem. Como as bebidas analisadas têm baixo teor de gordura estas tiveram boa aceitação em relação à consistência, mesmo após 28 dias de armazenamento. De uma maneira geral, o experimento $7(1,5 \%$ de Litesse e $1,5 \%$ de Dairy-1o) foi o que obteve o melhor sabor, consistência e aparência após 28 dias de armazenamento. 


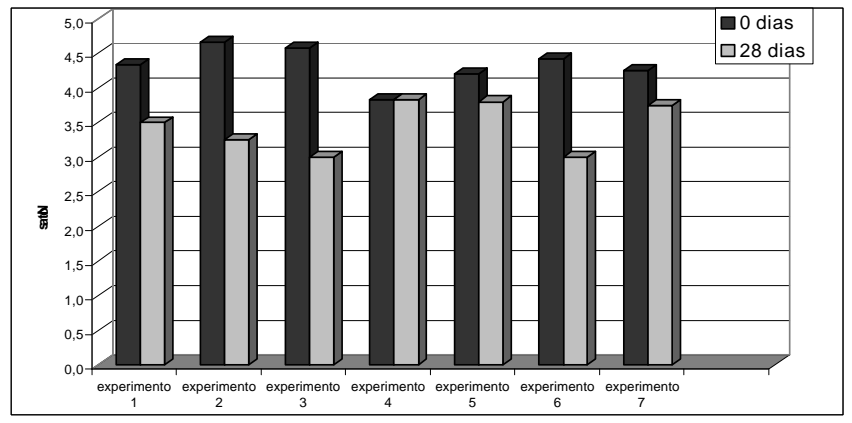

FIGURA 6. Avaliação sensorial da consistência das bebidas lácteas no dia da preparação e após 28 dias de armazenamento.

\section{4 - CONCLUSÕES}

1) A utilização de diferentes concentrações de Litesse e Dairy-lo não influenciou o comportamento fisico-químico das bebidas lácteas estudadas;

2) Sensorialmente foi constatado que o tempo de armazenamento não influenciou na aparência das bebidas lácteas;

3) O sabor foi o atributo mais afetado com o armazenamento;

4) Pode-se estabelecer 28 dias como o tempo ideal para a vida-de-prateleira das bebidas lácteas estudadas;

5) O experimento $7(1,5 \%$ de Litesse e $1,5 \%$ de Dairylo) foi o que obteve o melhor sabor, consistência e aparência após 28 dias de armazenamento;

6) Os resultados indicam que a utilização do Litesse e Dairy-lo em formulações de bebidas lácteas é perfeitamente viável.

\section{5 - REFERÊNCIAS BIBLIOGRÁFICAS}

[1] AKOH, C.C. Fat replacer. Food Technol., Chicago, v.52, p.4753, 1998.

[2] ALMEIDA, M. Dietético: nova lei. Nutri News, Rio de Janeiro, v., n.148, p.10-12, 1997.

[3] BARRANTES, E., TAMIME, A.Y. Production of low-calorie yoghurt using skim milk powder and fat substitute. III. Microbiological and organoleptic qualities. Milchwissenschaft, Munich, v.49, n.4, p.205-208, 1994.

[4] BARRANTES, E., TAMIME, A.Y., SWORD, A.M. Fat-free yogurtlike or dislike?. Dairy Ind. Int., London, v.58, n.11, p.3335, 1993.

[5] BOX, G.E.P., HUNTER, W.G., HUNTER, J.S. Statistics for experimenters. New York: Wiley, 1978. p.510-539.

[6] BRASIL. Ministério da Agricultura. Regulamento da inspeção industrial e sanitária de produtos de origem animal. Brasília: Ministério da Agricultura, 1980. (Aprovado pelo decreto 30.6912 de 29/03/1952 e alterado pelo Decreto 1255 de 25/06/1962).

[7] BRASIL. Ministério da Saúde. Secretária de Vigilância Sanitária. Portaria no 29 de 13 de Janeiro de 1998. In: LEGISLAÇÃO COMENTADA. De produtos lácteos e de alimentos para fins especiais- diet, light e enriquecidos, padrões de identidade e qualidade. São Paulo: Fonte Comunicações, 1998. p.123-130.

[8] CASAliS, J. Facteurs technologiques influençant la consistance, la textura, l"arôme ou le goût du yaourt. Ind. Aliment. Agric., Paris, v.3, p.1253-1262,.

[9] CASE, R.A., BRADLEY Jr., R.L., WILLIAMS, R.R. Chemical and physical methods. In: AMERICAN PUBLIC HEALTH ASSOCIATION. Standard methods for the examination of dairy products. 15 ed. New York: s.n., 1992. p.327404.

[10] DREWNOWSKI, A. The new fat replacement: a strategy for reducing fat consumption. Postgrad. Med., Minneapolis, v.87, p.111-121, 1990.

[11] ELLIS, M.J. Shelf life evaluation of foods. London: Black Academic \& Professional, 1996. 321p.

[12] GURGEL, M.S.C.A., OLIVEIRA, A.J. Avaliação das caracteristicas fisico-químicas do iogurte. Leite Derivados, São Paulo, v.22, p.38-43, 1995.

[13] HULL, M.E. Studies on milk proteins. II. Calorimetric determination of the partial hydrolysis of proteins in milk. J. Dairy Sci., Urbana, v.30, n.11, p.881-884, 1947.

[14] LABELL, F., O'DONNELL. C. (Low fat) Food for thought and marketplace realities. Prepared Foods, Highlands Ranch, v.166, n.2, p.47-42, 1997.

[15] LEWIS, M., DALE, R.H. Chilled yogurt and other dairy desserts. In: MAN, C.M.D., JONES, A.A. Shelf life evaluation of foods. New York: Blackie Academic \& Professional, 1996. 321p.

[16] MAN, C.M.D., JONES, A.A. Shelf life evaluation of foods. New York: Blackie Academic \& Professional, 1996. 321p.

[17] MARTIN, N.C., SKOKANOVA, J., LATRILLE, E., CORRIE, G. Influence of fermentation and storage conditions on sensory properties of plain low fat stirred yogurts. J. Sens. Stud., Trumbull, v.14, p.139-160, 1999.

[18] MISTRY, V.V., HASSAN, H.N. Manufacture of nonfat yogurt a high milk protein powder. J. Dairy Sci., Urbana, v.75, p.947-957, 1992.

[19] MUnÕS, A.M., CIVIlle, G.V., CARR, B.T. Sensory evaluation in quality control. New York: Van Nostrand Reinhold, 1992. 240p.

[20] NEY, K.H. Sensogamme, eine methodische Erwiterung der Aromagramme. Gondian, v.88, n.1, p.19, 1988.

[21] PENNA, A.L.B. Parâmetros reológicos de gomas para a fabricação de bebidas lácteas à base de soro. São Paulo: FCF/USP, 1997. 128p. [Monografia].

[22] PFEIFFER, C., D'AUJOURD'HUI, J.W., NUESSLI, J., ESCHER, F. Optimizing food packaging and shelf life. Food Technol., Chicago, v.53, n.6, p.52-59, 1999.

[23] ROSENTHAL, I. Milk and dairy products: properties and processing. New York: VCH, 1991. 217p.

[24] SIMPLESSE. O substituto natural da gordura: uma visão científica. 2.ed. S.1.: s.n., s.d., 13p. [Catálogo].

[25] SIVIERI, K., OLIVEIRA, M. N. Use of response surface methodology on rheologycal properties of lactic beverages added with fat mimetics (litesse and dairy-lo). IFT ANNUAL MEETING. Book of abstrats, Chicago, p.26, 2001.

[26] SOUZA, G. Fatores de qualidade do iogurte. Colet. Inst. Tecnol. Alim., Campinas, v.21, n.1, p.20-27, 1990.

[27] TAMIME, A.Y. Qualidade de iogurte elaborado com substitutos de gordura. In: LERAYER, A.L.S., SALVA, T.J.G., coords. Leites fermentados e bebidas lácticas. Campinas: ITAL, 1997. p.11-32. [Apostila].

[28] TAMIME, A.Y., BARRANTES, E., SWORD, A.M. The effect of starch based fat substitutes on the microstructure of 
set-style yogurt made from reconstituted skimmed milk powder. J. Soc. Dairy Technol., London, v.49, n.1, p.110, 1996.

[29] TAMIME, A.Y., ROBINSON, R.K. Science and technology. England: CRC Press, 1999. 368p.

[30] TRONCO, V.M. Manual para inspeção da qualidade do leite. Santa Maria: Editora da Universidade Federal de Santa Maria, 1997. 166p.
[31] ZADOW, J.G. Utilization of milk components: whey. In: Advances in milk processing. London: Chapman \& Hall, 1994. 485p.

\section{6 - AGRADECIMENTOS}

À Fundação de Amparo à Pesquisa do Estado de São Paulo "FAPESP" pela Bolsa de Doutorado. 